\title{
Knowledge, Attitude \& Practise of Voluntary Blood Donation in Students of BRLSABVM Medical College, Rajnandgaon, Chhattisgarh
}

\author{
Santosh Balgote ${ }^{1}$, Anshul Singhai ${ }^{2}$, Charuhas Akre ${ }^{3}$, Atul Deshkar ${ }^{4}$ \\ ${ }^{1}$ Associate Professor, Department of Physiology, Bharat Ratna Late Shree Atal Bihari Vajpayee Memorial Medical \\ College, Rajnandgfaon, (C.G.) , ${ }^{2}$ Assistant Professor, Department of Physiology, Bharat Ratna Late Shree Atal \\ Bihari Vajpayee Memorial Medical College, Rajnandgaon, (C.G), ${ }^{3}$ Associate Professor, Department of Community \\ Medicine, Govt. Medical College, Chandrapur (M.S.), ${ }^{4}$ Professor\& Head, Department of Physiology, Bharat Ratna \\ Late Shree Atal Bihari Vajpayee Memorial Medical College, Rajnandgaon, (C.G.)
}

\begin{abstract}
There is a crucial need for awaring people regarding blood donation all over the world. According to Census 2011 Rajnandgaon city, Chhattisgarh has 1,63114 population and only around 1000 Voluntary Blood Donation done per year ${ }^{3}$. This depicts the lack of knowledge and social awareness regarding the blood donation among the population of Rajnandgaon (C.G).

Material and Method: The present study is a cross sectional study and conducted among the students of the various graduate and post graduate colleges of Rajnandgaon, to assess their knowledge and attitudinal variables towards voluntary, non-remunerated blood donation.

Sample Size: It is calculated by using Kish and Lisle formula for cross-sectional studies ${ }^{8}$. Four hundred students were selected to participate in this study

Result: After analyzing the data, we observe that the overall knowledge regarding blood donation in study population was found to be $46.11 \%$. Most amazing thing is that 370 student out of 400 never did blood donation (92.5\%). Overall $30.60 \%$ of students have negative attitude towards blood donation which includes generalized tiredness after blood donation (10.12\%), hypovolemic anemia(15.12\%) and decrease in Immunity is (5.36\%). Around $69.40 \%$ of students have positive attitude and are willing to donate blood if they are demanded for blood donation (39.40\%), 3\% of non-donors not know much importance of blood donation and $27 \%$ don't know the procedure and place where to do blood donation.

Conclusion: Through this study we suggest that appropriate motivational campaign should be launched immediately among this young section of the population to convert this favourable "attitude" towards blood donation into a regular "practice" in order to increase the voluntary blood donation in Rajnandgaon.
\end{abstract}

Keyword: Voluntary blood donation, knowledge, attitude, practice, hypovolemic anemia.

\section{Corresponding Author:}

\section{Dr. Anshul Singhai}

Assistant Professor, Department of Physiology, Bharat

Ratna Late Shree Atal Bihari Vajpayee Memorial

Medical College, Rajnandgaon, (C.G.)

e-mail: dranshuljain5@gmail.com

\section{Introduction}

"More blood, more life ${ }^{1}$," lifesaving theme of World Blood Donor Day 2011 to express the importance of the crucial need for awaring people regarding blood donation all over the world. According to WHO, Around 93 million blood donors are donating blood annually all over the world ${ }^{2}$. Blood donation is one of the important 
components in saving the lives of many people in routine and emergency situations like in major surgery, pregnancy and childbirth, trauma etc. It has been observed that low income countries have nine times less donation as compared to high income countries, while day by day in the developing countries like India; the demand for blood supply has progressively increased. Various evidences indicate that there is a major shortage of blood and blood products in these countries.

As per the world health organization the minimum $1 \%$ blood donation must be done to meet the demand in given population, but according to Census 2011 Rajnandgaon city, Chhattisgarh has 1,63114 population and only around 1000 Voluntary Blood Donation done per year ${ }^{3}$. This depicts the lack of knowledge and social awareness regarding the blood donation among the population of Rajnandgaon (C.G).Acceptable age for blood donation is between 18 and 65 years $^{4}$. It has been worldwide reported that college students can be a very good source of quick and accessible quality blood, if they are motivated and recruited well as potential voluntary blood donors 5 . However, information from various blood banks in Rajnandgaon has shown that only onethirds of college students reported to have ever donated blood with varying reasons but many do not donate any longer.

The common reasons faced by college going students regarding Blood donation may be tight schedule at college, lack of knowledge and awareness of blood donation, fear of needle or infection, and lack of opportunity. In many countries, to understand factors that influence blood donationblood donation surveys have been used ${ }^{6}$.

There is no current published information on factors influencing voluntary blood donation among young people and among college students in Rajnandgaon. To fill that information gap, the study aimed at determining awareness, level of knowledge, and attitudes towards voluntary blood donation among university students by using the case of Rajnandgaon region. Such information would be vital in planning for raising awareness and helping young people to donate blood in the country.

\section{Aims and Objectives:}

Objectives of the study were as follows: To assess the level of knowledge regarding blood donation, among the undergraduate and post graduate college students in Rajnandgaon, CG.

To assess the attitudes, regarding the blood donation.

To assess the awareness about practices regarding blood donation.

\section{Material and Method}

The present study is a cross sectional study and conducted among the students of the various graduate and post graduate colleges of Rajnandgaon, to assess their knowledge and attitudinal variables towards voluntary, non-remunerated blood donation. The Rajnandgaon city has average literacy rate $86.83 \%$ with high rate $(94 \%)$ of college enrolment ${ }^{7}$.

Including and excluding criteria: We included all healthy adult male and female participating students willing for study. We excluded all visiting students and those who do not have consent to participate or having health related issues.

Sample size: It is calculated by using Kish and Lisle formula for cross-sectional studies ${ }^{\mathbf{8}}$. Four hundred students were selected to participate in this study and interviewed face to face on various aspects of blood donation using a structured questionnaire.

\section{Data Collection Tools and Procedures:} Questionnaires used in this study were self administrative paper-pencil questionnaire type. The filled questionnaires were collected by hand by the investigators on the same day after distributing them to the students. The questionnaire were developed from review from other pilot studies ${ }^{9,10}$. Questionnaire contains questions related to socio-demographic characteristics of participants.

Few questions were based on the awareness and knowledge of blood donation. While few questions was related to attitudes towards blood donation which were of "yes/no" answer type, and some questions were on attitude towards blood donation. A part of questionnaire was devoted to collect the source of information regarding blood donation and lastly there are questions related to reasons for donating and not donating blood with open ended type questions. 


\section{Observation and Results}

Table No. 1: Knowledge towards blood donation

\begin{tabular}{|l|c|}
\hline Knowdge & Percentage (\%) \\
\hline Age criteria for blood Donation & 67.82 \\
\hline Weight criteria for blood donation & 70.34 \\
\hline Blood pressure range for blood donation & 54.22 \\
\hline Maximum blood donation per year & 36.25 \\
\hline Quantity of blood volume withdraw each time & 20.63 \\
\hline Up to how many days blood can be store & 16.40 \\
\hline What are the different blood groups & 70.31 \\
\hline Lives saved through each unit of blood & 26.21 \\
\hline Benefits of blood donation & 52.81 \\
\hline Over all percentage of knowledge & 46.11 \\
\hline
\end{tabular}

Table No. 2: Attitude towards blood donation

\begin{tabular}{|l|c|}
\hline Attitude & 92.5\% (Never did blood donation) \\
\hline Blood donation causes generalized tiredness & Negative $10.12 \%$ \\
\hline It causes hypovolemic anemia & Negative $15.12 \%$ \\
\hline It hampers the Immunity & Negative $5.36 \%$ \\
\hline Nobody asked or motivated for blood donation & Positive $39.40 \%$ \\
\hline Non-donors don't know importance of blood donation & Positive $3 \%$ \\
\hline Don't know what to do and where to do blood donation & Positive $27 \%$ \\
\hline
\end{tabular}

Table No. 3: Practice on blood donation

\begin{tabular}{|l|c|}
\hline Reason for not a regular donor & $7.5 \%$ \\
\hline Lake of privacy while procedure & $28.37 \%$ \\
\hline Students felt uneasiness after donation & $9.23 \%$ \\
\hline Students donated blood only once & $7.5 \%$ \\
\hline Never asked or motivated again for blood donation & $62.40 \%$ \\
\hline Willing to voluntary donateblood if they are demanded for blood donation & $69.40 \%$ \\
\hline
\end{tabular}

After analyzing the data, we observe that the overall knowledge regarding blood donation in study population was found to be $46.11 \%$ (Table 1). Most amazing thing is that 370 student out of 400 never did blood donation (92.5\%). Overall $30.60 \%$ of students have negative attitude towards blood donation which includes generalized tiredness after blood donation (10.12\%), hypovolemic anemia(15.12\%) and decrease in Immunity is $(5.36 \%)$ (Table 2$)$. Around $69.40 \%$ of students have positive attitude and are willing to donate blood if they are demanded for blood donation (39.40\%), 3\% of nondonors not know much importance of blood donation and $27 \%$ don't know the procedure and place where to do blood donation. We observed that only 30 students (7.5\%) donated blood once(Table 2). We found that amongst the blood donors, $28.37 \%$ of donors said there is lake of privacy while procedure, around $9.23 \%$ felt uneasy after donation and $62.40 \%$ said they are never asked or motivated for blood donation(Table 3).

\section{Discussion}

Day by day due to population growth hike and other factors like medical emergency, Road traffic accidents the demand of blood and its substitute is tremendously 
increased. In spite of available resources and facilities the number of voluntary blood donation is quit less. As per the world health organization the minimum $1 \%$ blood donation must be done to meet the demand in given population, but according to Census 2011 Rajnandgaon city, Chhattisgarh has 1,63114 population and only around 1000 Voluntary Blood Donation done per year. This depicts the lack of knowledge and social awareness regarding the blood donation among the population of Rajnandgaon (C.G).It has been worldwide reported that college students can be a very good source of quick and accessible quality blood, if they are motivated and recruited well as potential voluntary blood donors. So in this study we tried to fill that gap between demand and attitude towards voluntary blood donation.

In the above study we found that students have average knowledge $(46.11 \%)$ regarding blood donation. If we educate them regarding health benefit of blood donation and eradicating the myth towards the various false fact like donation causes anemia, weakness we can change the negative attitude (30.6\%) in them.

The common reasons faced by college going students regarding Blood donation are lack of knowledge and awareness of blood donation, fear of needle or infection, and lack of opportunity (39.40\%). By motivating them this figure can be easily added in voluntary blood donation.

\section{Conclusion and Implication}

Recruiting a sufficient number of safe blood donors in India is an emerging challenge especially with the increase in demands as a result of an increase in population size and an increase in the number of medical facilities. The present study was conducted in Rajnandgaon city in order to understand the various factors contributing to beliefs, attitudes, and level of knowledge associated with blood donation and transfusion that will help the blood centre in building and maintaining an adequate and safe blood supply. The current study was aimed to reflect a general lack of information regarding donation policies and practices among the surveying individuals.

It is also possible that an increased availability of correct information on donation requirement to more eligible potential donors may help persuade some of them to donate. Through this study we suggest that appropriate motivational campaign should be launched immediately among this young section of the population to convert this favourable "attitude" towards blood donation into a regular "practice" in order to increase the voluntary blood donation in Rajnandgaon.

Conflict of Interest: None Declared

Source of Funding: No funding Sources

Ethical Clearance: This study was approved by the Institutional Committee.

\section{References}

1. Albert Farrugia, More blood, more life? Reflections on World Blood Donor Day - 2011 Indian J Med Res. 2011 Jun; 133(6): 573-576.

2. Based on data from the WHO Global Database on Blood Safety, 2008.

3. Censusindia.gov.in. 2011 census,xii-a district census handbook rajnandgaon village $\&$ town.

4. WHO.int/campaigns/world-blood-donorday/2018/who-can-give-blood,WHO Guidelines on assessing donor suitability for blood donation.

5. Babita Raghuwanshi et.al,Voluntary Blood Donation among Students - A Cross-Sectional Study on Knowledge and Practice vs. Attitude, J Clin Diagn Res. 2016 Oct; 10(10): EC18-EC22.

6. Vox Sang. 2012 Jul;103(1):64-74. doi: 10.1111/j.1423-0410.2012.01600.x. Epub 2012 Mar 23.

7. Rajnandgaon City Population Census 2011-2020, Chhattisgarh.

8. Jaykaran Charan et.al, How to Calculate Sample Size for Different Study Designs in Medical Research? Indian J Psychol Med. 2013 Apr-Jun; 35(2): 121-126.doi: 10.4103/0253-7176.116232.

9. Habtom Woldeab Gebresilase et.al, Knowledge, attitude and practice of students towards blood donation in Arsi university and Adama science and technology university: a comparative cross sectional study, Gebresilase et al. BMC Hematology (2017) 17:20 DOI 10.1186/s12878-017-0092-x.

10. Benedict Nwogoh, Knowledge, Attitude, and Practice of Voluntary Blood Donation among Healthcare Workers at the University of Benin Teaching Hospital, Benin City, Nigeria, Hindawi Publishing Corporation Journal of Blood Transfusion Volume 2013, Article ID 797830, 6 pages http://dx.doi.org/10.1155/2013/797830. 